https://doi.org/10.48009/2_iis_2005_238-243

\title{
PUBLICATION TRENDS IN TECHNOLOGY MEDIATED LEARNING (TML): A RECENT RETROSPECTIVE
}

\author{
Dr. Mark Ward, Southern Illinois University Edwardsville, mward@siue.edu
}

\begin{abstract}
Online learning is purportedly one of the most rapidly growing forms of TML. The popular press often touts the impressive advances and potential gains of this training and educational tool. Given both the preeminence and rapidly changing nature of this phenomenon, it is important to examine what trends have developed in its short history. This study provides a brief retrospective of this history by examining the number of articles published in both peer-reviewed journals and popular publications (e.g., trade journals and magazines) over the last 11 years. Of special note is the somewhat surprising influence of the so-called "dot-com bust" on publication rates. The results and ramifications of these results are discussed.
\end{abstract}

Keywords: technology mediated learning, peer-review journals, trade journals, online learning,

\section{INTRODUCTION}

Online learning is a pervasive and growing phenomenon often referenced in the popular press. Just recently, a National Public Radio broadcast featured the expanding use of online courses in public school education for nontraditional students with special (social) needs [1]. The Washington Post also noted the impressive growth of the Washington D.C.-based Blackboard, an incorporated online learning service provider [2]. USA Today recently touted the merits of nurturing gifted children with online courses that could be adjusted to match the (usually rapid) pace at which these students can absorb the material [3]. The scholarly press has likewise shown a great interest in the already-realized gains made resulting from online technology and the potential for future advances in this highly-specialized form of training and education.

\section{Technology Mediated Learning (TML)}

Many researchers use online learning and TML somewhat interchangeably [4, 5]. TML proper can be defined as any training or educational encounter that is substantially mediated through an automated information system [6]. While it is true that online learning is accurately described as a subset of TML, the term "online" has become almost synonymous with the notion that the individual (who is "online") is separated from some substantive portion of the educational resource. For example, students can be geographically separated from teachers or databases (e.g., servers) in the online environment. Following this convention, this study views online learning as a subset of TML.

\section{Overview}

The next section of this research puts forward the methodology used to examine this literature, namely a search of two comprehensive databases containing numerous scholarly journals, trade journals, and magazines. The results of this examination are then put forwarding, comparing the 
rise and fall of pertinent publication rates in both databases. Concluding remarks explore the ramifications of these findings.

\section{METHODOLOGY}

Two online databases, Academic Search Elite (ASE) and Business Source Elite (BSE), were searched. As one might discern from the names of the databases, ASE is a large, eclectic database of about 1,500 peer-reviewed journals and an additional 1,900 trade journals and magazines for a total of 3,476 titles. BSE is more focused on management and marketing scholarly publications that number about 500 and an additional 1,300 trade journals and magazines for a total of 1,800 titles. Note that scholarly journals are peer-reviewed publications that are primarily read by the academic community. Trade publications and magazines are not peer-reviewed and are primarily read by the general public.

The search was conducted by examining data that covered an 11-year period, ranging from January 1994 to December 2004. A keyword search using several common TML phrases (i.e., distance education, distance learning, online education, online learning) were used to explore the databases. The search looked for matches of these keywords in the subject area, keywords, titles, and abstracts of all articles in these sources. The search engines of these databases allow the use of Boolean operators to refine exploration, and qualifiers were implemented. For example, some articles contained more than one set of keyword phrases. For instance, a single article might contain the phrases distance education and online learning. To prevent counting the article more than once, Boolean operators were used (e.g., search for distance education, NOT distance learning, NOT online education, NOT online learning).

\section{RESULTS}

These databases listed 10,492,078 articles, published between January 1994 and December 2004. Of that number, 5,187 articles were identified from the search using TML-oriented keywords. All of the figures illustrate data from that period, 1994-2004.

Of the peer-reviewed literature in the ASE database, it is perhaps not surprising that no articles mention online learning and only one article mentions online education between 1994 and 1995. The Internet was still relatively new and not approved for profit-making activities until 1995 [7]. As online technology matured and become more accessible (and, therefore, more pervasive) one can note a relatively steep growth curve in the number of articles exploring TML. Interestingly, the total number of articles peaks in 2001 at 578 and then drops to 478 in 2002.

Of the peer-reviewed literature in the BSE Elite database, no articles mention online education or online learning between 1994 and 1995. As with the ASE data, one can note a relatively steep growth curve in the number of articles exploring TML. The total number of articles peaks in 2002 (84) and then drops in 2003 (50).

A comparison between the total number of TML peer-reviewed journals that appear in both the ASE and BSE appear in Figure 1. 
Figure 2 illustrates TML (both databases) peer-reviewed articles as a percentage of all peerreviewed articles. TML trade publication and magazine articles as a percentage of all non-peerreviewed articles is also presented. (Note that for readability the data have been magnified by $10^{4}$. For example, the 2.67 value in 1994 represents $10^{-4}$ x 2.67 or .000267 percent of all peerreview TML articles published during that year from both databases.)

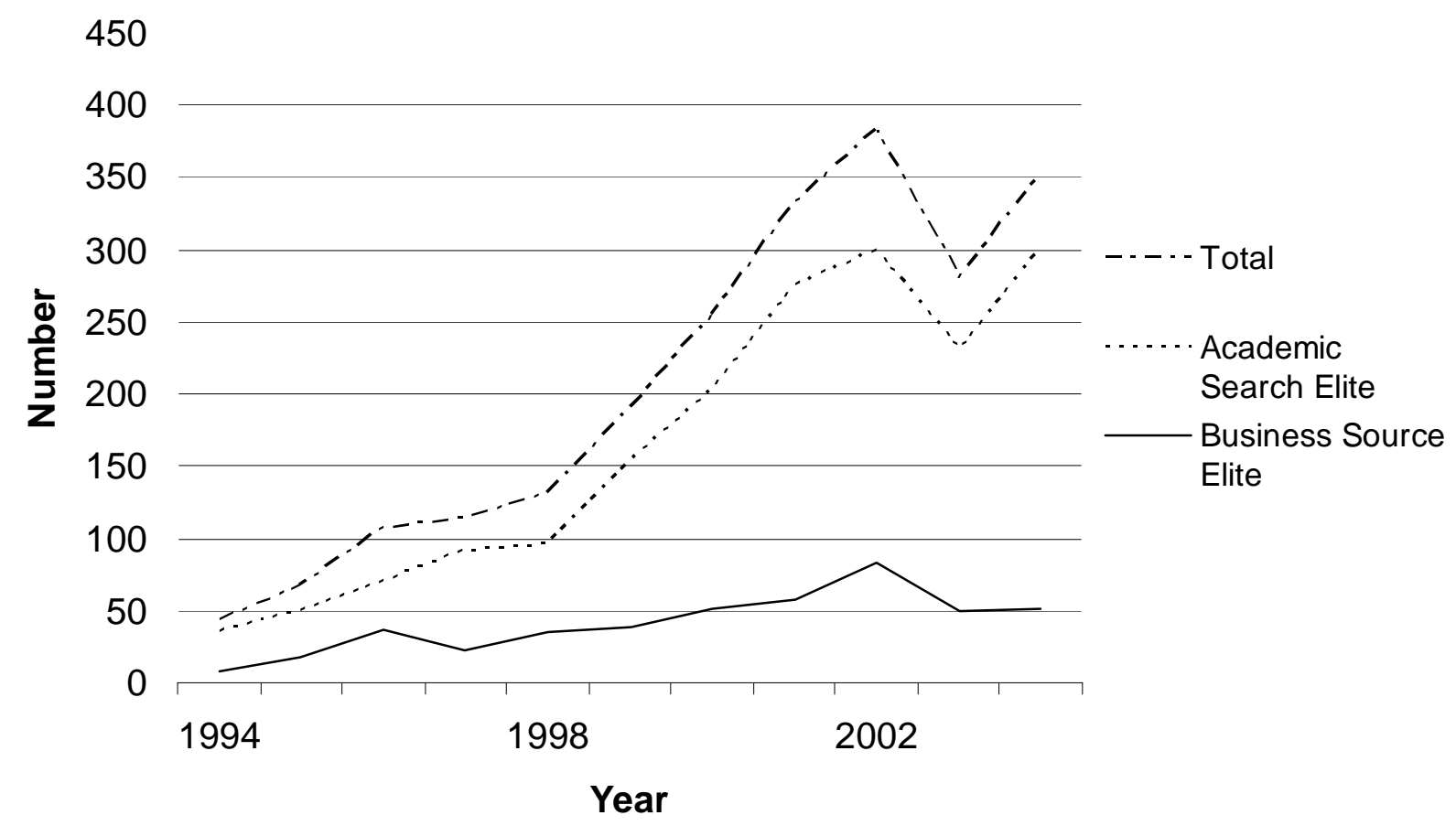

Figure 1. Academic Source Elite versus Business Source Elite Peer-review: 1994-2004 


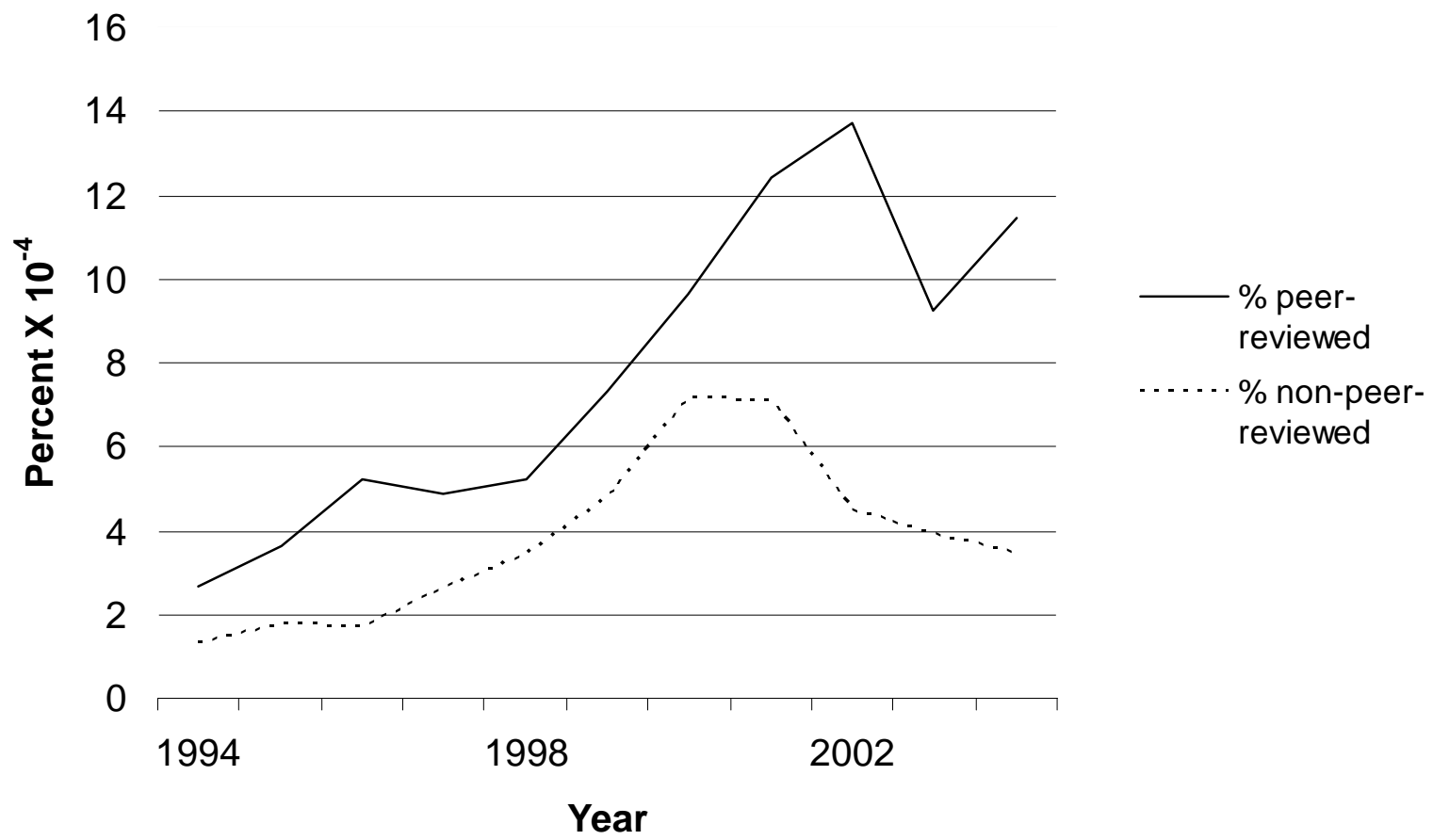

Figure 2. Technology Mediated Learning_Peer versus Non-peer-reviewed: 1994-2004

Figure 3 portrays the percentage of TML peer-reviewed articles that appear in the ASE database juxtaposed against the same type of journals that appear in the BSE. As one can note by the observing the figure, there is almost no difference in the relative percentages between the two databases even though BSE is more business-oriented than ASE. 


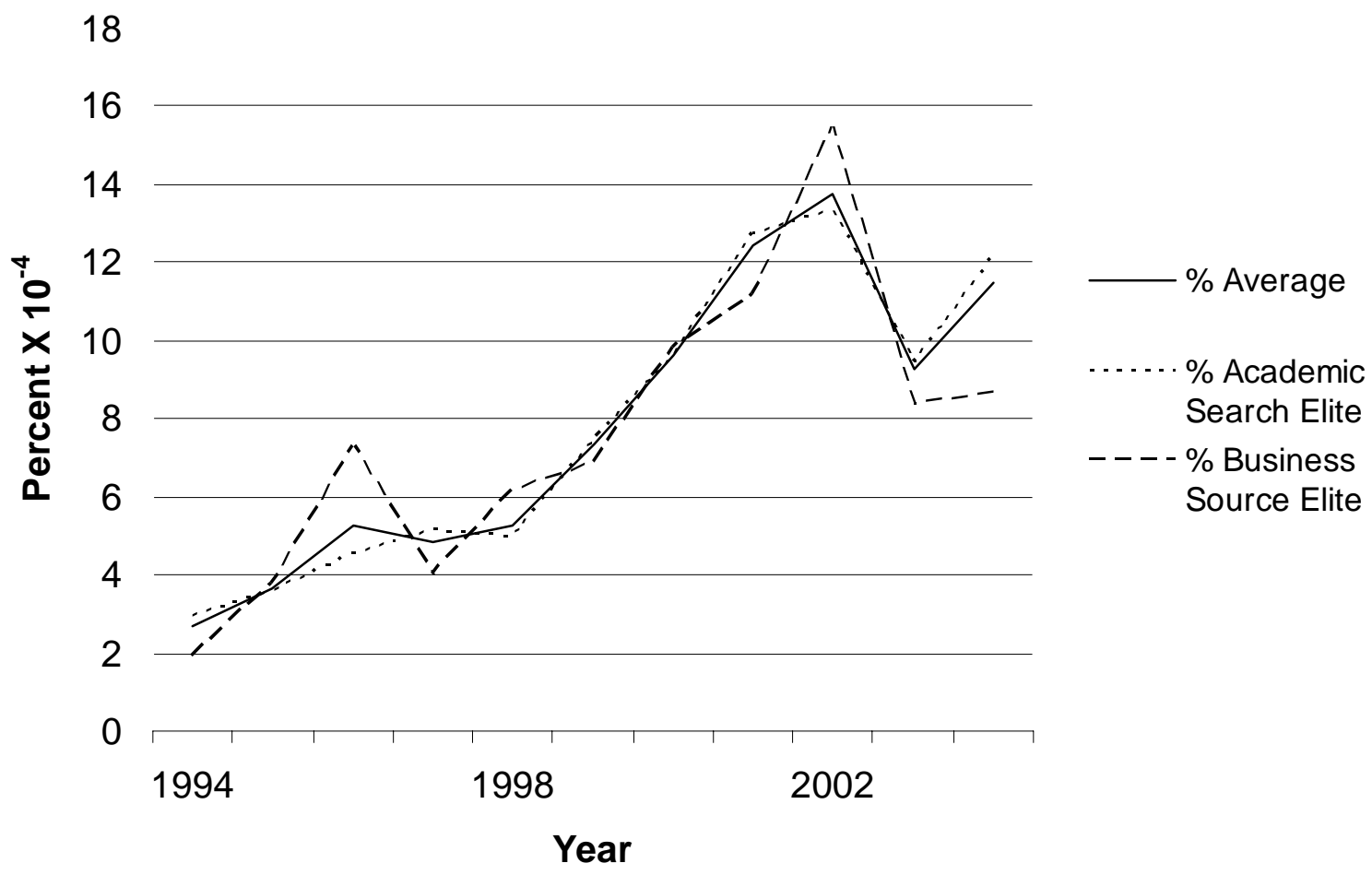

Figure 3. Technology Mediated Learning Peer-reviewed Comparisons: 1994-2004

\section{DISCUSSION}

One of the most interesting aspects of these data is the precipitous drop in peer-reviewed TML journal articles from 2001 to 2003 and a similar drop in trade journals and magazines from 2000 to 2001. As Figure 2 illustrates, what is remarkable is that both types of articles show a consistent rise in number that nearly parallel each other until 2001. Indeed, when one applies a Pearson product moment correlation coefficient to assess the degree of correlation between the peer-reviewed and non-peer-reviewed data from 1994 to 2000, it produces a statistically significant (at the .01 level) correlation coefficient, $r=.955$. That is, one could argue that the percentage of publications produced by these disparate sources are nearly mirror images of each other until some point after 2000 .

Important questions remain: Why did this close association between peer-reviewed and the popular press end in 2000? Why did the trade journal and magazine article number drop two years before the academic press begins to fall? One possibility can be gleaned by examining important events taking place at the time. Early in 2000, many new telecommunication corporations, especially organizations heavily vested in the Internet, began to fail (the so called "dot-com" bust). The explanation might be as simple as a rapidly shrinking interest in a declining industry leads to fewer trade journal and magazine articles. Notwithstanding this possibility, why would the academic press have a peak that crests one to two years later than the mainstream press? The answer may lie in the fact that peer-reviewed manuscripts can take several months or even years to get into print. Hence, a large number of manuscripts may have arrived at the 
editors' offices of scholarly journals in early 2000, shortly before the economic downturn. The majority of these manuscripts that were accepted for publication probably did not end up in print until some point after late 2001.

\section{CONCLUSION}

TML continues to rank as an important topic as evidenced by the recent large number of peerreviewed articles that appear in both databases. In fact, despite the drop in scholarly journals published in 2003 because of the downturn in the economy three years previously, one can note a dramatic rise in the number of TML articles the very next year, 2004 (an increase of 72 articles or $26 \%)$.

Perhaps one of the most important ramifications of this study is that it tends to reinforce the notion that the scholarly community tends to be several months or even years behind when analyzing significant contemporary events (e.g., dot-com bust) that take place in the environment. In some venues, this may not be a problem. However, in rapidly changing situations (such as those found on the cutting-edge of technology), this relatively slow response could be more problematic. There is no easy substitute for the needed analytical rigor nurtured by the peer-review process. Nevertheless, if applied research is rendered irrelevant because it is too dated, the degree of rigor may also become mute. A possible remedy is for editors to divide research into basic and applied subject areas. Since basic research tends to be somewhat "ageless," the review process may be less time sensitive with respect to these manuscripts. Applied research, on the other hand, could be subject to a more rapid review process. Of course, this solution is not perfect. If all applied research is advanced in a manuscript queue, basic research could languish for years. Perhaps some middle ground can be found. For example, from the time that a scholar submits a manuscript to Issues in Information Systems and has it published (assuming acceptance) is about eight months. By academic standards, this is fairly rapid and applied research can remain relatively viable in this journal. On the other hand, since the journal is peer-reviewed, analytical precision is also maintained.

\section{REFERENCES}

1. Hansen, L. (Author). (2005, January 23: 1:00-2:00 PM Eastern Time). Profile: Increase in online learning. Weekend Edition Sunday. Washington, DC: National Public Radio.

2. In brief. (2004, November 10). The Washington Post, p. E05.

3. Vanderkam, L. (2004, September 28). Online learning: A smart way to nurture gifted kids. USA Today, p. 13A.

4. Alavi, M. \& Leidner, D. E. (2001). Research commentary: Technology-mediated learning-a call for greater depth and breadth of research. Information Systems Research, 12(1), 2-10.

5. Alavi, M. \& Gallupe, R. B. (2003). Using information technology in learning: Case studies in business and management education programs. Academy of Management Learning \& Education, 2(2), 139-143.

6. Leidner, D. E. \& Jarvenpaa, S. L. (1995). The use of information technology to enhance management school education: a theoretical view. MIS Quarterly, 19(3), 265-291.

7. Ward, M. A. (2004). Internet diffusion public policy in the U.S.: A critique. Ethics \& Critical Thinking Journal, 18(4), 57-73. 